\title{
Adsorptive Separation Studies of $\beta$-Carotene from Methyl Ester Using Mesoporous Carbon Coated Monolith
}

\author{
M. Muhammad, ${ }^{1}$ Moonis Ali Khan, ${ }^{2}$ and T. S. Y. Choong ${ }^{3,4}$ \\ ${ }^{1}$ Department of Chemical Engineering, Faculty of Engineering, Malikussaleh University Aceh, Lhokseumawe, Indonesia \\ ${ }^{2}$ Chemistry Department, College of Science, King Saud University, Riyadh 11451, Saudi Arabia \\ ${ }^{3}$ INTROP, Universiti Putra Malaysia, Selangor, 43400 Serdang, Malaysia \\ ${ }^{4}$ Department of Chemical and Environmental Engineering, Faculty of Engineering, Universiti Putra Malaysia, Selangor, \\ 43400 Serdang, Malaysia
}

Correspondence should be addressed to T. S. Y. Choong; tsyc2@eng.upm.edu.my

Received 10 January 2012; Revised 17 May 2012; Accepted 23 May 2012

Academic Editor: Saima Q. Memon

Copyright (C) 2013 M. Muhammad et al. This is an open access article distributed under the Creative Commons Attribution License, which permits unrestricted use, distribution, and reproduction in any medium, provided the original work is properly cited.

Adsorption of $\beta$-carotene on mesoporous carbon coated monolith (MCCM) from methyl ester as a solvent was investigated. Kinetics and thermodynamics parameters have been evaluated. Maximum $\beta$-carotene adsorption capacity was $22.37 \mathrm{mg} / \mathrm{g}$ at $50^{\circ} \mathrm{C}$. Process followed Langmuir isotherm. The adsorption was endothermic and spontaneous. Contact time studies showed increase in adsorption capacity with increase in $\beta$-carotene initial concentration and temperature. Pseudo-second-order model was applicable to the experimental data. The value of activation energy confirmed physical adsorption process.

\section{Introduction}

The characteristic orange color of crude palm oil is due to the presence of carotenoids ( $\alpha$ - and $\beta$-carotenes). These carotenoids are of commercial importance as they are utilized as natural coloring agents in edible and pharmaceutical products. Transesterification of palm oil produces an ecofriendly diesel (or biodiesel) containing methyl ester as a major constituent. The biodiesel (or methyl ester) contains a rather high concentration of carotenoids. Therefore, it is essential to develop a method to recover this valuable product. Separation of carotenoids from methyl ester by nanofiltration was reported by Darnoko and Cheryan [1].

The utility of carbonaceous (powder and granular) materials in the form of fixed bed for separation is associated with high pressure drops, potential channeling, and many other demerits. Compared to carbonaceous material, mesoporous carbon coated monolith (MCCM) has large external surface area and a very less pressure drop across fixed bed MCCM column. High mechanical stability and thermal expansion coefficient are some of the other properties of MCCM. The MCCM columns can also be placed in vertical or horizontal position and in mobile system without deforming shape and is easier to be scaled up due to its simple design and uniform flow distribution.

In our previous studies, we had reported the adsorption and desorption of $\beta$-carotene on MCCM using isopropyl alcohol and $n$-hexane as solvents $[2,3]$. In this study we had utilized MCCM for adsorptive separation of $\beta$-carotene form methyl ester in synthetic solution system. Various thermodynamics and kinetics parameters were studied.

\section{Materials and Methods}

2.1. Materials. Cordierite monoliths (channel width 1.02 $\pm 0.02 \mathrm{~mm}$ and wall thickness $0.25 \pm 0.02 \mathrm{~mm}$ ) were obtained from Beihai Huihuang Chemical Packing Co., Ltd, China. Others materials like $\beta$-carotene was purchased from Sigma-Aldrich, Malaysia. The stock solution of $\beta$-carotene $(500 \mathrm{mg} / \mathrm{L})$ was prepared by dissolving required amount in solvent.

2.2. Chemical and Reagents. Methyl ester, a solvent for $\beta$ carotene was purchased from Sigma-Aldrich, Malaysia. Furfuryl alcohol (FA), pyrrole, and poly(ethylene glycol) (PEG, 
MW-8000) were purchased from Fluka, Malaysia. Nitric acid $\left(\mathrm{HNO}_{3}\right)$ 65\% was purchased from Fisher, Malaysia. All the chemicals used were of analytical grade.

2.3. Preparation of MCCM. The polymerization of samples was carried out by mixing FA and PEG in percentage volume ratio of $40: 60$. The polymerization catalyst, $\mathrm{HNO}_{3}$, was added stepwise, at every $5 \mathrm{~min}$. After addition of the acid, the mixture was stirred for an hour while maintaining temperature at approximately $21-23^{\circ} \mathrm{C}$. Detailed method of MCCM preparation was reported elsewhere [2].

2.4. Adsorption Equilibrium and Kinetics. Batch adsorption experiments were carried out under nitrogen atmosphere. $\beta$-carotene of concentrations 50 to $500 \mathrm{mg} / \mathrm{L}$ were taken in $250 \mathrm{~mL}$ conical stopper cork flasks. Methyl ester was used as a solvent. The MCCM, $0.8 \mathrm{~g}$, was added to each flask. The flasks were wrapped with aluminium foil to minimize $\beta$-carotene photo degradation. The flasks were shaken at $150 \mathrm{rpm}$ in a water bath shaker (Stuart SBS40) at desired temperatures (30, 40 and $50^{\circ} \mathrm{C}$ ). At equilibrium, the samples were collected and were analyzed.

Kinetics studies were carried out under similar experimental conditions. The MCCM, $3 \mathrm{~g}$, was taken in $250 \mathrm{~mL}$ conical flasks for reaction with $\beta$-carotene. Samples were collected at desired time intervals using a digital micropipette (Rainin Instrument, USA). The samples were analyzed using a double beam UV/VIS spectrophotometer (Thermo Electron Corporation) at wavelength $446 \mathrm{~nm}$.

The concentration of solute adsorbed on the MCCM at equilibrium was calculated as

$$
q_{e}=\frac{V\left(C_{0}-C e\right)}{m}
$$

where $q_{e}$ is the solid phase concentration at the equilibrium phase $(\mathrm{mg} / \mathrm{g}), C_{0}$ and $C_{e}$ are the initial and equilibrium concentrations of the liquid phase $(\mathrm{mg} / \mathrm{L}), V$ is the liquid volume (L), and $m$ is the adsorbent mass $(\mathrm{g})$.

\section{Results and Discussion}

3.1. Equilibrium Isotherms. Langmuir isotherm implies formation of monolayer coverage of adsorbate on the surface of the adsorbent. A linearized form is given as

$$
\frac{C_{e}}{q_{e}}=\frac{1}{K_{L} b}+\frac{1}{b} C_{e},
$$

where $K_{L}$ is Langmuir adsorption equilibrium constant $(\mathrm{L} / \mathrm{mg})$, and $b$ is the monolayer capacity of the adsorbent (mg/g).

Freundlich isotherm describes equilibrium on heterogeneous surfaces where adsorption energies are not equal to all adsorption sites. Linear form is given as

$$
\log q_{e}=\log K_{F}+1 / n \log C_{e}
$$

where $K_{F}$ is the Freundlich constant for a heterogeneous adsorbent $(\mathrm{mg} / \mathrm{g})(\mathrm{L} / \mathrm{mg})^{1 / n}$, and $n$ is the heterogeneity factor.
TABLE 1: Isotherm parameters for $\beta$-carotene adsorption on MCCM at different temperatures.

\begin{tabular}{lcccc}
\hline Isotherms & Parameters & $30^{\circ} \mathrm{C}$ & $40^{\circ} \mathrm{C}$ & $50^{\circ} \mathrm{C}$ \\
\hline \multirow{4}{*}{ Langmuir } & $b$ & 20 & 21.23 & 22.37 \\
& $K_{L}$ & 0.0053 & 0.0064 & 0.0079 \\
& $R_{L}$ & 0.28 & 0.24 & 0.20 \\
& $R^{2}$ & 0.9803 & 0.9944 & 0.9919 \\
\hline \multirow{4}{*}{ Freundlich } & $K_{F}$ & 0.61 & 0.96 & 1.43 \\
& $1 / n$ & 0.52 & 0.46 & 0.42 \\
& $R^{2}$ & 0.9597 & 0.9842 & 0.9658 \\
\hline
\end{tabular}

TABLE 2: Comparative monolayer adsorption capacities $(b)$ for $\beta$ carotene at $50^{\circ} \mathrm{C}$.

\begin{tabular}{lccc}
\hline Adsorbent & $b(\mathrm{mg} / \mathrm{g})$ & Solvent & Reference \\
\hline MCCM & 62.12 & Isopropyl alcohol & {$[2]$} \\
Silica gel & 25.32 & $n$-hexane & {$[5]$} \\
Florisil & 86.21 & $n$-hexane & {$[5]$} \\
MCCM & 22.37 & Methyl ester & This study \\
\hline
\end{tabular}

The coefficient of determination $\left(R^{2}\right)$ values for Langmuir model at 30,40 , and $50^{\circ} \mathrm{C}$ were higher compared to Freundlich model showing better applicability of Langmuir model (Table 1). These results were in good agreement with previously reported studies on $\beta$-carotene adsorption on acid-activated montmorillonite [4] and on silica-based adsorbent [5]. However, for $\beta$-carotene adsorption from crude maize and sunflower oil on acid-activated bentonite, applicability of Freundlich model was reported [6]. The values of $b$ and $K_{L}$ generally increased with increasing temperature. Table 2 compares $\beta$-carotene maximum adsorption capacity $(b)$ with literature.

The separation factor $\left(R_{L}\right)$ is a dimensionless parameter. It is defined as

$$
R_{L}=\frac{1}{1+K_{L} C_{0}}
$$

The $R_{L}$ values for the present study were in range of favorable adsorption process (Table 1).

3.2. Effect of Temperature. The $\beta$-carotene adsorption increases with temperature (Figure 1) suggesting that the intraparticle diffusion rate of the adsorbate molecules into the pores increased with increase in temperature since diffusion is an endothermic process [7]. Physical adsorption is normally considered to be the dominant adsorption mechanism for temperature lower than $100^{\circ} \mathrm{C}$ and chemisorption for temperature higher than $100^{\circ} \mathrm{C}$ [8]. The pigment is adsorbed only on the outer surface of the adsorbent at lower temperatures, and both on the outer surface and pore surface at higher temperatures [9]. However, at higher temperature destruction of $\beta$-carotene may occur [5]. Therefore, the adsorption experiments were carried out up to $50^{\circ} \mathrm{C}$. 


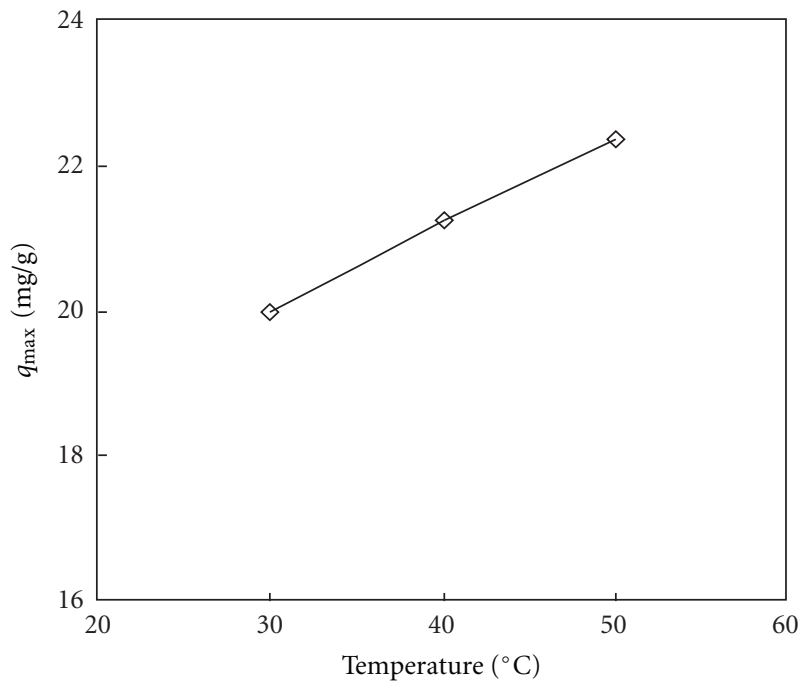

Figure 1: Effect of temperature on $\beta$-carotene adsorption onto MCCM.

3.3. Estimation of Thermodynamic Parameters. The data obtained from the Langmuir isotherm can be used to determine thermodynamic parameters such as Gibbs free energy change $(\Delta G)$, enthalpy change $(\Delta H)$, and entropy change $(\Delta S)$. The Gibbs free energy change was calculated as

$$
\Delta G=-R T \ln b,
$$

where $T$ is the absolute temperature $(\mathrm{K})$ and $R$ is the universal gas constant $(8.314 \mathrm{~J} / \mathrm{mol}-\mathrm{K})$. The $\Delta H$ and $\Delta S$ values were determined from the following equation:

$$
\ln b=\frac{\Delta S}{R}-\frac{\Delta H}{R T}
$$

The $\Delta G$ values at 30,40 , and $50^{\circ} \mathrm{C}$ were -7546.7 , -7951.23 , and $-8345.7 \mathrm{~J} / \mathrm{mol}$, respectively. The decrease in $\Delta G$ values with temperature suggests that more $\beta$-carotene is adsorbed with increasing temperature [10]. This implies that the adsorption is favored at higher temperature. The positive $\Delta H$ value $(4560.31 \mathrm{~J} / \mathrm{mol})$ indicates that the adsorption is endothermic. The positive $\Delta S$ value $(39.96 \mathrm{~J} / \mathrm{mol}-\mathrm{K})$ suggests increasing randomness at the solid/liquid interface during $\beta$ carotene adsorption on MCCM.

3.4. Effect of Contact Time. The experiments were performed varying temperature (i.e., 30,40 and $50^{\circ} \mathrm{C}$ ) at a fixed initial $\beta$ carotene concentration $(500 \mathrm{mg} / \mathrm{L})$. An increase in reaction temperature causes a decrease in solution viscosity leading to an increase in $\beta$-carotene molecules rate of diffusion across the external boundary layer and into the internal pores of the adsorbent. In addition, an increase in temperature increases MCCM equilibrium capacity for $\beta$-carotene. As shown in Figure 2 , the recovery of $\beta$-carotene increased with increase in temperature. This may be the result of increase in the $\beta$ carotene molecules movement with temperature. An increasing number of molecules may also acquire sufficient energy to undergo an interaction with active sites. As presented

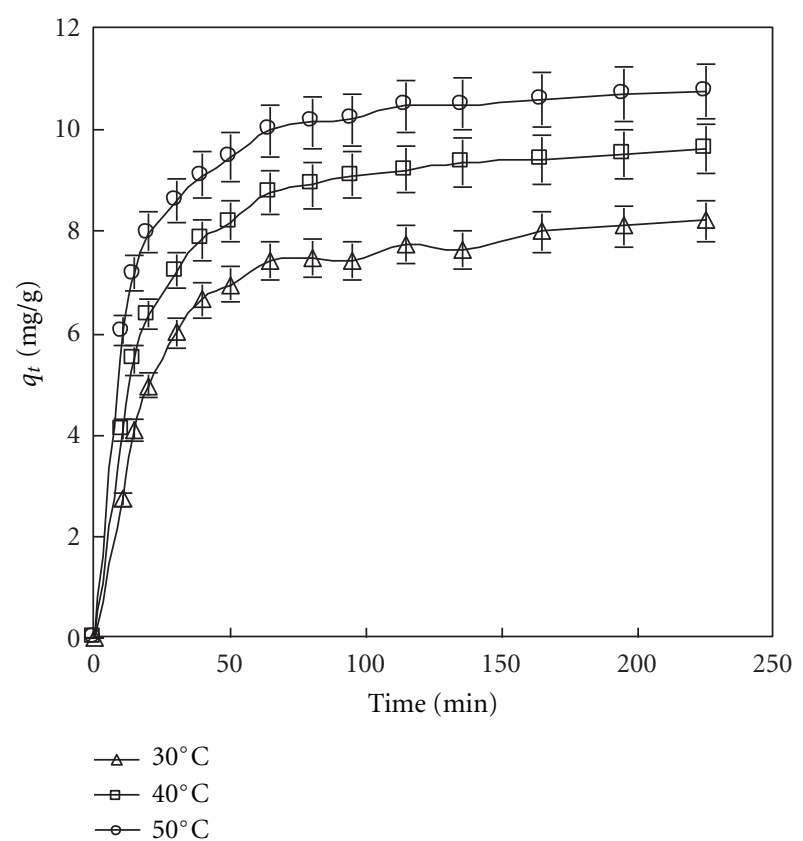

FIGURE 2: Effect of contact time on $\beta$-carotene adsorption on MCCM at different temperatures (initial $\beta$-carotene concentration-500 mg/L).

in Table 3 the $\beta$-carotene adsorption capacity onto MCCM increased from 8.218 to $10.775 \mathrm{mg} / \mathrm{g}$ with an increase in reaction temperature from 30 to $50^{\circ} \mathrm{C}$, indicating that the process is endothermic [11]. The equilibration time at various temperatures was $200 \mathrm{~min}$.

$\beta$-carotene adsorption on MCCM for various adsorbate concentrations was fast initially, thereafter, the adsorption rate decreased slowly as the available adsorption sites decreases gradually (Figure 3 ). The equilibration time increases from 165 to $200 \mathrm{~min}$ while the adsorption capacity increases from 3.099 to $10.775 \mathrm{mg} / \mathrm{g}$ with increase in concentration from 50 to $500 \mathrm{mg} / \mathrm{L}$ (Table 3 ).

3.5. Adsorption Kinetics. Lagergren rate equation is one of the most widely used adsorption rate equations to describe the adsorption kinetics. Linearized form is expressed as [12]:

$$
\log \left(q_{e}-q_{t}\right)=\log \left(q_{e}\right)-\frac{k_{1}}{2.303} t
$$

where $q_{e}$ and $q_{t}$ are the adsorbed amount at equilibrium and at time $t$ and $k_{1}$ is the pseudo-first-order rate constant $(1 / \mathrm{min})$.

The pseudo-second-order model in linearized form is expressed as [13]

$$
\frac{t}{q_{t}}=\frac{1}{k_{2} q_{e}^{2}}+\frac{1}{q_{e}} t,
$$

where $k_{2}$ is the rate constant of pseudo-second-order sorption (g/mg-min).

The values of $R^{2}$ for pseudo-second-order model were comparatively higher. The calculated adsorption capacity $\left(q_{e, \text { calc }}\right)$ values for pseudo-second-order model were much 
TABLE 3: Kinetics data for $\beta$-carotene adsorption on MCCM.

\begin{tabular}{lccccccc}
\hline \multirow{2}{*}{ Temp $\left({ }^{\circ} \mathrm{C}\right)$} & \multirow{2}{*}{$C_{0}(\mathrm{mg} / \mathrm{L})$} & $q_{e, \text { exp. }}(\mathrm{mg} / \mathrm{g})$ & \multicolumn{3}{c}{ Pseudo-first-order } & \multicolumn{3}{c}{ Pseudo-second-order } \\
& & $q_{e, \text { calc. }}(\mathrm{mg} / \mathrm{g})$ & $k_{1}(1 / \mathrm{min})$ & $R^{2}$ & $q_{e, \text { calc. }}(\mathrm{mg} / \mathrm{g})$ & $k_{2}(\mathrm{~g} / \mathrm{mg}-\mathrm{min})$ & $R^{2}$ \\
\hline 50 & 50 & 3.099 & 1.842 & 0.0221 & 0.9791 & 3.262 & 0.0249 \\
50 & 250 & 5.969 & 2.818 & 0.0235 & 0.9475 & 6.203 & 0.9997 \\
50 & 500 & 10.775 & 5.212 & 0.0237 & 0.9576 & 11.186 & 0.0187 \\
30 & 500 & 8.218 & 4.756 & 0.0196 & 0.9311 & 8.772 & 0.9998 \\
40 & 500 & 9.615 & 5.145 & 0.0216 & 0.9548 & 10.152 & 0.9999 \\
\hline
\end{tabular}

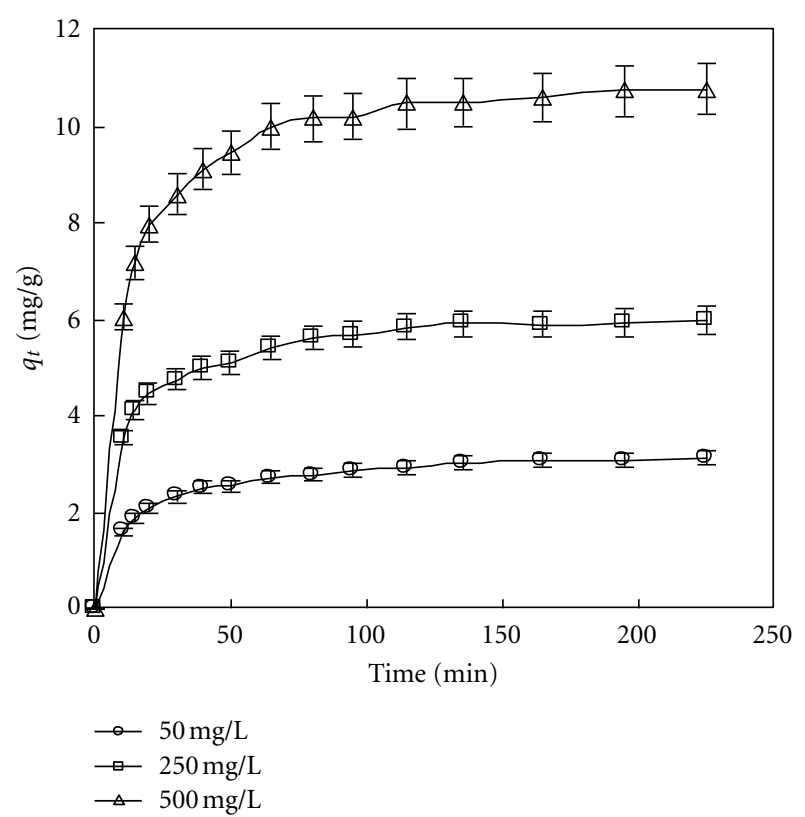

FIgURE 3: Effect of contact time on $\beta$-carotene adsorption on $\mathrm{MCCM}$ at different concentrations at $50^{\circ} \mathrm{C}$.

closer to experimental adsorption capacity $\left(q_{e, \text { exp }}\right)$ values (Table 3). Therefore, it is concluded that the pseudosecond-order kinetics model better describes $\beta$-carotene onto MCCM. Similar results were reported for $\beta$-carotene adsorption on acid activated bentonite $[10,14]$ and florisil [5].

3.6. Adsorption Mechanism. The rate-limiting step prediction is an important factor to be considered in sorption process. For solid-liquid sorption process, the solute transfer process was usually characterized by either external mass transfer (boundary layer diffusion) or intraparticle diffusion or both. The mechanism for $\beta$-carotene removal by adsorption may be assumed to involve three successive transport steps: (i) film diffusion, (ii) intraparticle or pore diffusion, and (iii) sorption onto interior sites. The last step is considered negligible as it is assumed to be rapid. $\beta$-carotene uptake on MCCM active sites can mainly be governed by either liquid phase mass transfer or intraparticle mass transfer rate.

The most common method used to identify the mechanisms involved in the adsorption process is by fitting the

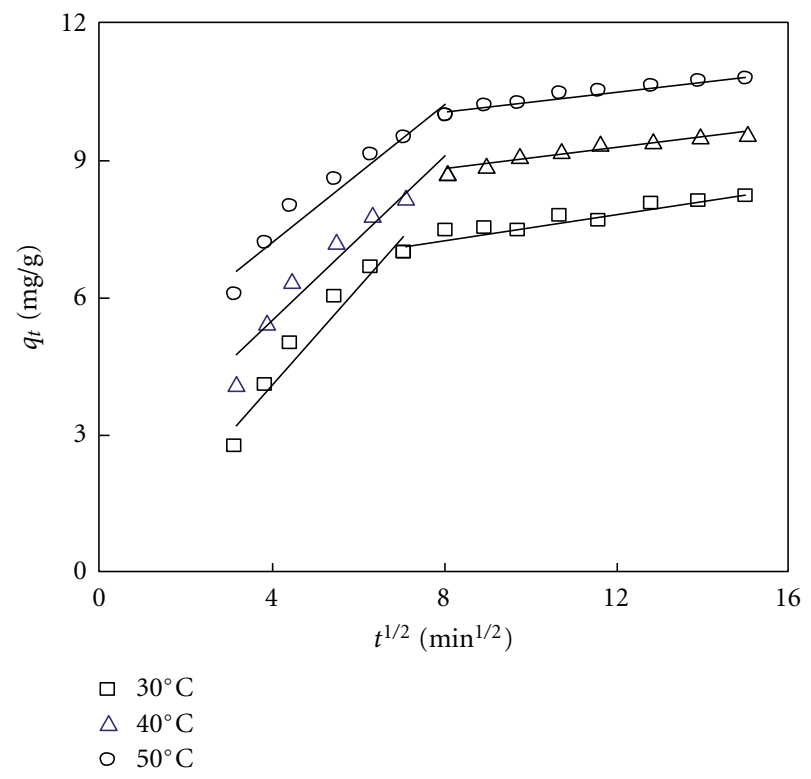

Figure 4: Weber and Morris plot for $\beta$-carotene adsorption at different temperatures (Initial $\beta$-carotene concentration was $500 \mathrm{mg} / \mathrm{L}$ ).

experimental data to the intraparticle diffusion plot. The intraparticle diffusion equation can be expressed as [15]

$$
q_{t}=k_{\mathrm{id}} t^{1 / 2}
$$

where $k_{\mathrm{id}}$ is intraparticle diffusion rate constant $(\mathrm{mg} / \mathrm{g}$ $\min ^{1 / 2}$ ).

The Weber-Morris plots of $q_{t}$ versus $t^{1 / 2}$ were presented in Figures 4 and 5 , for the $\beta$-carotene adsorption onto MCCM as a function of temperature and initial concentration. For the adsorption process to be intraparticle diffusion controlled, the plots of $q_{t}$ versus $t^{1 / 2}$ should pass through the origin and the $R^{2}$ should be sufficiently close to unity. The intraparticle diffusion parameters, $k_{\mathrm{id}}$, for these regions were determined from the slope of the plots.

The adsorption data for $q_{t}$ versus $t^{1 / 2}$ for the initial period show curvature, attributed to boundary layer diffusion effects or external mass transfer effects [16]. As shown in Figures 4 and 5 the adsorption process followed two phases, suggesting that the adsorption process proceeded first by surface adsorption and then intraparticle diffusion. This demonstrated that, in the initial stages, adsorption was due 
TABLE 4: Intraparticle diffusion parameters for $\beta$-carotene adsorption on MCCM.

\begin{tabular}{lccccrr}
\hline Temp. $\left({ }^{\circ} \mathrm{C}\right)$ & Conc. $(\mathrm{mg} / \mathrm{L})$ & $q_{e, \text { exp. }}(\mathrm{mg} / \mathrm{g})$ & $k_{\mathrm{id}, 1}\left(\mathrm{mg} / \mathrm{g}-\mathrm{min}^{1 / 2}\right)$ & $R^{2}$ & $k_{\mathrm{id}, 2}\left(\mathrm{mg}^{2} / \mathrm{g}-\mathrm{min}^{1 / 2}\right)$ & 0.0675 \\
\hline 50 & 50 & 3.099 & 0.2448 & 0.9505 & 0.9160 \\
50 & 250 & 5.969 & 0.3542 & 0.9439 & 0.0706 \\
50 & 500 & 10.775 & 0.7540 & 0.9445 & 0.1133 \\
30 & 500 & 8.218 & 1.0631 & 0.9490 & 0.1239 \\
40 & 500 & 9.615 & 0.8993 & 0.9372 & 0.9537 \\
\hline
\end{tabular}

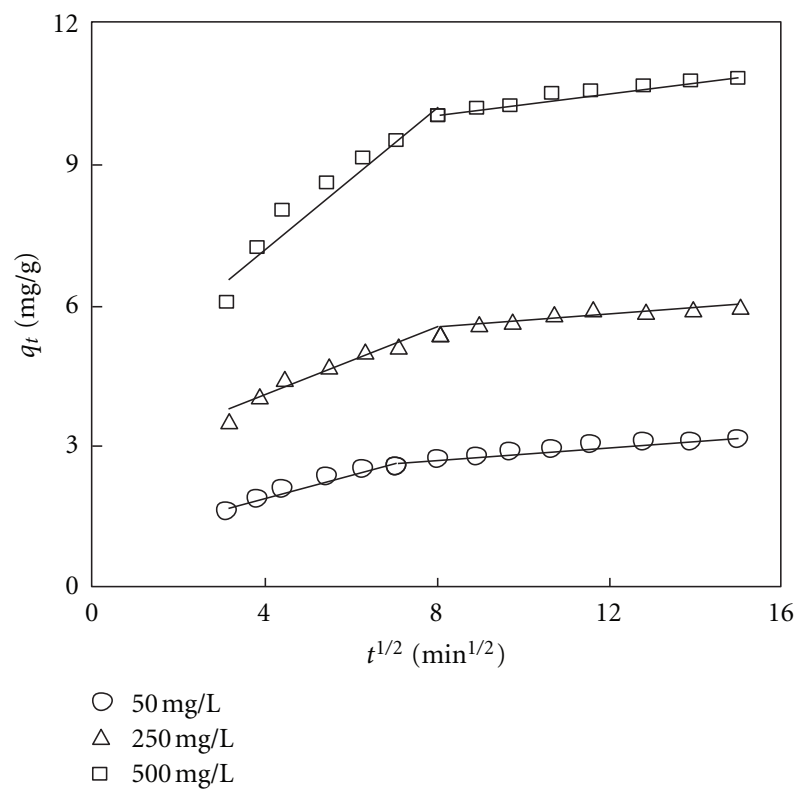

FIGURE 5: Weber and Morris plot for $\beta$-carotene adsorption at different initial concentrations and temperatures $50^{\circ} \mathrm{C}$.

to the boundary layer diffusion effect and subsequently due to the intraparticle diffusion effect [17].

The Weber-Morris plots did not pass through the origin (Figures 4 and 5), implying that the mechanism of adsorption was influenced by two or more steps of adsorption process. This also indicates that the intraparticle diffusion is not the sole rate-controlling step. The values of rate parameters of intraparticle diffusion $\left(k_{\mathrm{id}, 1}\right.$ and $\left.k_{\mathrm{id}, 2}\right)$ and correlation coefficients $\left(R^{2}\right)$ were presented in Table 4 . The intraparticle diffusion rate increases with increase in initial $\beta$-carotene concentration and reaction temperature. The driving force of diffusion was very important for adsorption processes. Generally driving force changes with $\beta$-carotene concentration in bulk solution. The increase in $\beta$-carotene concentration and reaction temperature result in increase of the driving force, which in turn increases the diffusion rate of $\beta$-carotene molecules in monolith pores.

3.7. Determination of Activation Energy. The values of rate constant found from adsorption kinetics could be applied in the Arrhenius form to determine the activation energy.
The relationship between the rate constants and solution temperature is expressed as

$$
k_{2}=k_{0} \exp \left(-\frac{E_{a}}{R T}\right)
$$

where $k_{0}$ is the temperature independent factor, $E_{a}$ is the activation energy $(\mathrm{kJ} / \mathrm{mol}), R$ is the gas constant $(8.314 \mathrm{~J} / \mathrm{mol}$ $\mathrm{K})$, and $T$ is the solution temperature (K). Equation (10) could be transformed into a linear form as

$$
\log k_{2}=\log k_{0}-\frac{E_{a}}{2.303 R T}
$$

The values of $E_{a}$ and $k_{0}$ were obtained from the slope and intercept of the plot $\log k_{2}$ versus $1 / T$ (figure not shown).

As shown in Table 3, the values of rate constant for pseudo-second-order $\left(k_{2}\right)$ were found to increase from 0.0073 to $0.0105 \mathrm{~g} / \mathrm{mg}$-min, with increasing solution temperature from $303.15\left(30^{\circ} \mathrm{C}\right)$ to $323.15 \mathrm{~K}\left(50^{\circ} \mathrm{C}\right)$. The magnitude of activation energy could provide information on type of adsorption, either physical or chemical. The value of activation energy for $\beta$-carotene adsorption was $14.73 \mathrm{~kJ} / \mathrm{mol}$. This value was $<42.0 \mathrm{~kJ} / \mathrm{mol}$ and is therefore consistent with physical adsorption process [18]. Adsorption of $\beta$-carotene by an acid-activated bentonite [6], sorption of $\beta$-carotene and chlorophyll onto acid-activated bentonite [10], and the sorptions of $\beta$-carotene on tonsil [19] have been reported to be controlled by physical adsorption.

\section{Conclusions}

$\beta$-carotene adsorption studies onto MCCM from methyl ester solution were conducted. Langmuir was the best applicable isotherm model with maximum monolayer adsorption capacity $22.37 \mathrm{mg} / \mathrm{g}$ at $50^{\circ} \mathrm{C}$. The adsorption process was endothermic and followed physisorption mechanism. Kinetics studies showed applicability of pseudo-second-order kinetics model. The activation energy was $14.73 \mathrm{~kJ} / \mathrm{mol}$, suggesting that $\beta$-carotene adsorption onto MCCM is via physical adsorption.

\section{Acknowledgment}

The authors would like to acknowledge Universiti Putra Malaysia for financial support of this project (partially via vot: 9199659). 


\section{References}

[1] D. Darnoko and M. Cheryan, "Carotenoids from red palm methyl esters by nanofiltration," Journal of the American Oil Chemists' Society, vol. 83, no. 4, pp. 365-370, 2006.

[2] Muhammad, T. S. Y. Choong, T. G. Chuah, R. Yunus, and Y. H. T. Yap, "Adsorption of $\beta$-carotene onto mesoporous carbon coated monolith in isopropyl alcohol and $n$-hexane solution: equilibrium and thermodynamic study," Chemical Engineering Journal, vol. 164, no. 1, pp. 178-182, 2010.

[3] Muhammad, M. A. Khan, T. S. Y. Choong, T. G. Chuah, R. Yunus, and Y. H. T. Yap, "Desorption of $\beta$-carotene from mesoporous carbon coated monolith: isotherm, kinetics and regeneration studies," Chemical Engineering Journal, vol. 173, no. 2, pp. 474-479, 2011.

[4] N. Sarier and C. Güler, " $\beta$-Carotene adsorption on acidactivated montmorillonite," Journal of the American Oil Chemists Society, vol. 65, no. 5, pp. 776-779, 1988.

[5] A. L. Ahmad, C. Y. Chan, S. R. Abd Shukor, and M. D. Mashitah, "Adsorption kinetics and thermodynamics of $\beta$-carotene on silica-based adsorbent," Chemical Engineering Journal, vol. 148, no. 2-3, pp. 378-384, 2009.

[6] G. E. Christidis and S. Kosiari, "Decolorization of vegetable oils: a study of the mechanism of adsorption of $\beta$-carotene by an acid-activated bentonite from cyprus," Clays and Clay Minerals, vol. 51, no. 3, pp. 327-333, 2003.

[7] K. Li, Z. Zheng, X. Huang, G. Zhao, J. Feng, and J. Zhang, "Equilibrium, kinetic and thermodynamic studies on the adsorption of 2-nitroaniline onto activated carbon prepared from cotton stalk fibre," Journal of Hazardous Materials, vol. 166, no. 1, pp. 213-220, 2009.

[8] M. H. Ma and C. I. Lin, "Adsorption kinetics of $\beta$-carotene from soy oil using regenerated clay," Separation and Purification Technology, vol. 39, no. 3, pp. 201-209, 2004.

[9] H. B. W. Patterson, Bleaching and Purifying Fats and Oils, AOCS Press, Champaign, Ill, USA, 1992.

[10] Z. Wu and C. $\mathrm{Li}$, "Kinetics and thermodynamics of $\beta$-carotene and chlorophyll adsorption onto acid-activated bentonite from Xinjiang in xylene solution," Journal of Hazardous Materials, vol. 171, no. 1-3, pp. 582-587, 2009.

[11] Y. Bulut and H. Aydin, "A kinetics and thermodynamics study of methylene blue adsorption on wheat shells," Desalination, vol. 194, no. 1-3, pp. 259-267, 2006.

[12] S. Lagergren, "About the theory of so-called adsorption of soluble substances," Kungliga Svenska Vetenskapsakademiens, Handlingar, vol. 24, no. 4, pp. 1-39, 1898.

[13] Y. S. Ho and G. McKay, "The kinetics of sorption of divalent metal ions onto sphagnum moss peat," Water Research, vol. 34, no. 3, pp. 735-742, 2000.

[14] J. Tong, Z. Wu, X. Sun, X. Xu, and C. Li, "Adsorption kinetics of $\beta$-carotene and chlorophyll onto acid-activated bentonite in model oil," Chinese Journal of Chemical Engineering, vol. 16, no. 2, pp. 270-276, 2008.

[15] W. J. Weber and J. C. Morris, "Kinetics of adsorption on carbon from solution," Journal of the Sanitary Engineering Division, vol. 89, pp. 31-59, 1963.

[16] G. McKay, M. S. Otterburn, and A. G. Sweeney, "The removal of colour from effluent using various adsorbents. III. Silica: rate processes," Water Research, vol. 14, no. 1, pp. 15-20, 1980.

[17] B. E. Wang, Y. Y. Hu, L. Xie, and K. Peng, "Biosorption behavior of azo dye by inactive CMC immobilized Aspergillus fumigatus beads," Bioresource Technology, vol. 99, no. 4, pp. 794-800, 2008.
[18] D. L. Sparks, Environmental Soil Chemistry, Academic Press, San Diego, Calif, USA, 1995.

[19] L. E. Khoo, F. Morsingh, and K. Y. Liew, "The Adsorption of $\beta$-Carotene I. by bleaching earths," Journal of the American Oil Chemists Society, vol. 56, no. 7, pp. 672-675, 1979. 

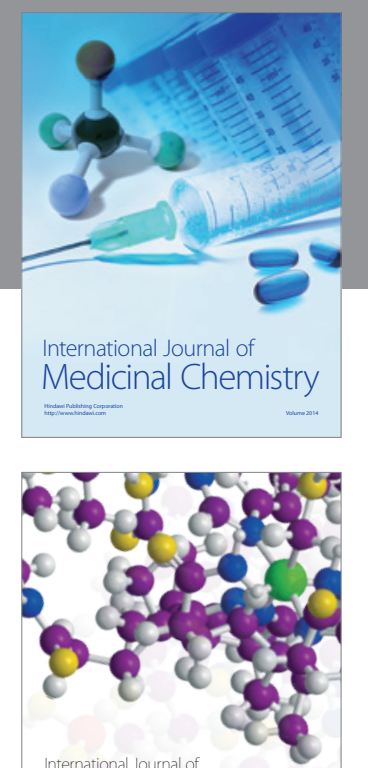

\section{Carbohydrate} Chemistry

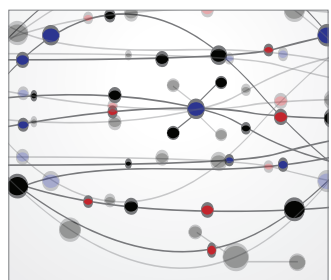

The Scientific World Journal
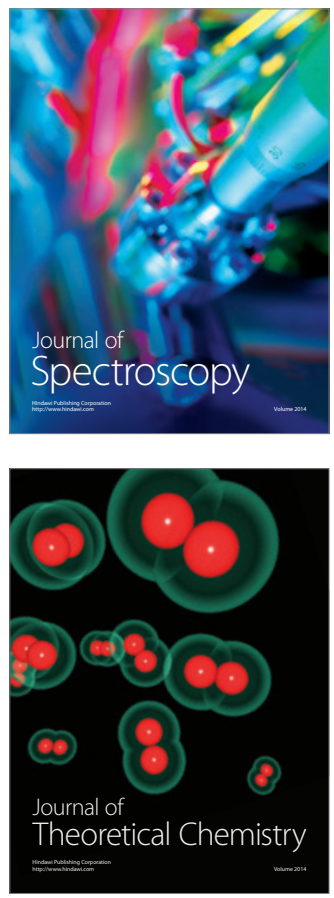
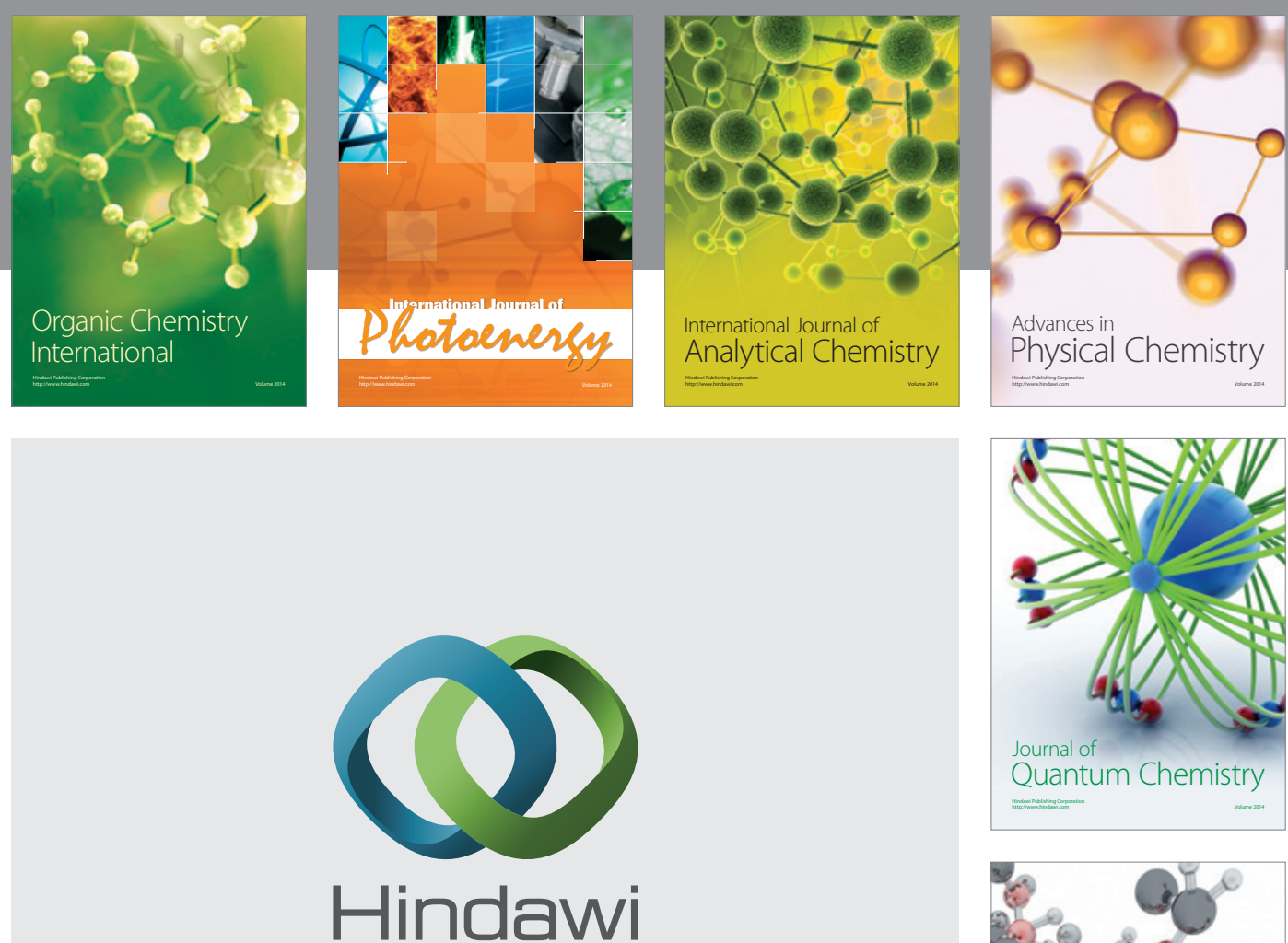

Submit your manuscripts at

http://www.hindawi.com

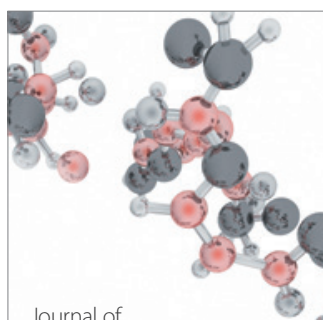

Analytical Methods

in Chemistry

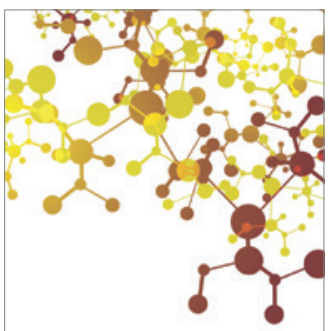

Journal of

Applied Chemistry

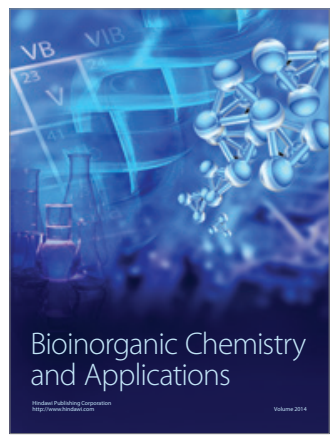

Inorganic Chemistry
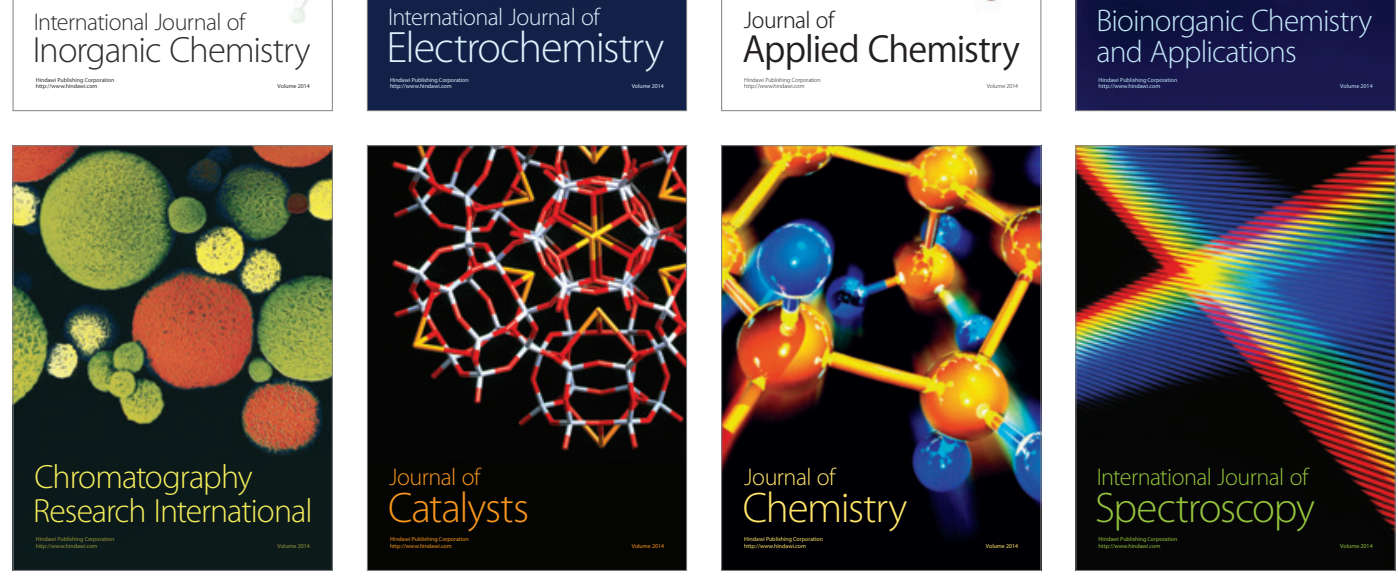